\title{
Towards a Model for Dynamic Formation and Operation of Virtual Organizations for Transportation
}

\author{
Daniel Cabrera-Paniagua ${ }^{1}$, Galo Herrera ${ }^{1}$, Claudio Cubillos ${ }^{2}$, Makarena Donoso ${ }^{2}$ \\ ${ }^{1}$ Escuela de Ingeniería Comercial, Universidad de Valparaíso, \\ Pasaje La Paz 1301, Viña del Mar, Chile, \\ daniel.cabrera@uv.cl; galo.herrera@uv.cl \\ 2 Escuela de Ingeniería Informática, Pontificia Universidad Católica de Valparaíso, \\ Av. Brasil 2241, Valparaíso, Chile, \\ claudio.cubillos@ucv.cl; makarena.donoso@ucv.cl
}

\begin{abstract}
This work presents an approach in the establishment of a model for dynamic formation and operation of virtual organizations, devoted to the domain of urban transport of people, particularly in the demand-responsive transportation domain. This model adds flexibility in integrating new transportation operators, based on new business opportunities that can be observed during the operation of the transport service. Also, this approach provides mechanisms to assist in maintaining the required minimum levels of quality. A general schema based on Agent Technology that supports the proposed dynamic model is included.
\end{abstract}

Keywords: Virtual Enterprise, Demand-Responsive Transportation Systems, Agents, Flexibility.

\section{Introduction}

The current competitive market conditions make companies act efficiently and effectively to adequately satisfy their customers' needs, while complying with the legislation in this field of action. Among the alternatives that companies have to improve their competitiveness are quality certified processes, innovative marketing strategies, management systems, customer relations, among other initiatives. In this sense, one of the complementary ways companies have to overcome barriers to entry and / or survive in highly competitive markets is the formation of strategic alliances. These alliances allow the elaboration of joined-action plans based on the definition of common objectives for the participant organizations of the alliance. Thus, each participating organization focuses its efforts in the optimization of individual capacities and the maximization of its benefits, through a mutual collaboration with another organizations and the externalization of processes which have no direct relation to its particular line of business. Precisely in this ambit takes force the concept of virtual enterprise, which informally corresponds to a cooperation modality between enterprises, based on collaboration agreements among legally independent organizations, which while considering commons objectives, share resources, knowledge, infrastructure, among others. All this is supported by information technologies. Important aspects to consider in a virtual enterprise context are for example, to clearly define the alliance goals to achieve over time, because this allows selecting later the participant organizations within the alliance.

Furthermore, the time and conditions of staying inside the alliance is another crucial aspect, because in an essential sense, the cooperation is supported on a common understanding of business, plus the trust and the mutual responsibility in the achievement of the alliance success. A virtual enterprise is a temporal alliance of enterprises [2]. For this, the temporal continuity of this alliance is a very important aspect.

In another sense, in some countries of Europe, North America and Asia there have been carried out during the last thirty years various projects and studies devoted to optimize the use of resources and increase the quality of service in the passenger transportation domain $[1][3][4][5][7]$. The passenger transportation domain is a very important aspect in countries development, because this arises as consequence of the daily activities that people perform in diverse areas (production, education, recreational activities, among others), that is called System of Activities [6]. One specialized area in this context corresponds to the Demand-Responsive Transportation [7] that in simple terms seeks to adapt the available offer of transportation service to the level of observed demand, considering the particular objectives of the transportation service provider, and users of the transportation system.

This work presents a model of dynamic formation of virtual organizations devoted to 
the passenger transportation domain. This model considers the evaluation of the permanence of a transportation operator inside the transportation virtual enterprise, as well as the dynamic incorporation of new transportation operators, depending on the level of estimated transactions, operating conditions, availability of transportation operators, among other conditions. This model is mapped to a general schema based on Agent Technology. An agent will be understood according to what described by Weiss [19]: "An agent is a computer system that is situated in some environment, and that is capable of autonomous action in this environment in order to meet its design objectives". In this sense, the agent technology allows to add autonomy, delegation, cooperation and competition properties to IT solutions. Furthermore, it can provide distributed negotiation architectures for diverse domains such as transportation [10] and supply chain planning [22] among others.

The novelty of our work relies on: 1) the conceptualization of a flexible model of virtual organization, 2) the application of dynamism and control in the life-cycle of a virtual transportation enterprise as study case, and 3) the application of agent technology as first approach to implement a simulation software.

\section{Related Work}

Various initiatives have been observed in the field of virtual enterprises [14] [15] [13] [8], to include only a few. In 2008, Folinas et. al. [14] suggested a conceptual framework for modelling business processes in virtual organizations through the introduction of Web Services technology. Web services can be facilitators for this type of business organizations and are particularly well suited to satisfy the needs arising in the dynamism of current markets. As the Internet reduces costs of interaction between organizations, partnerships between organizations is seen as a means to achieve economic benefits in the short term, and competitive advantage in the long run. That is why the interest in the creation of virtual organizations has increased.

In another sense, Petersen et. al. [16] proposed the use of software agents in the formation of virtual enterprises. The particular focus of the authors is the description of the partners' selection process and the services provided by each of them. The virtual enterprise partners are represented by software agents. The authors present the formation of a virtual enterprise in the context of an electronic marketplace, where several companies compete to become members of a virtual enterprise. Software agents and Web services are used as technological base. The purpose of this work is based on the understanding of a virtual enterprise from an organizational perspective. The emphasis is on ensuring that the proposal is not addressed by technology, but rather, is a combination of organizational design ideas and appropriate technologies.

Although the work of Petersen et. al. refers to the process of virtual enterprises' formation, the existing literature does not mention the virtual enterprises formation process targeted to the domain of passenger transportation in response to demand, and particularly, nor makes emphasis on the temporal continuity of the transportation operators that built up the network of companies. Mintzberg said [20]: "organizations are structured to capture and direct flow systems and to define the interrelationships between the various parties. These flows and relationships are not linear". In the context of urban passenger transportation under a virtual enterprise organizational scheme, the flexibility is crucial, because it is essential to frequently check the quality level of the service offered to the transportation system users, and implement all necessary initiatives to ensure the provision of a high-quality service.

This work represents a continuation of the work developed by Cabrera and Cubillos [10], who proposed a software framework for the domain of urban transportation of people in a response to demand mode that used the concept of virtual enterprise as referential organizational model for the companies participating in the provision of transportation service. The virtual enterprise model considered was the one presented by Strader et al.[18], a model of a generic life cycle for virtual enterprises, which was informally adapted to the domain of passenger transportation in response to demand.

\section{Virtual Enterprises}

Formally, a virtual enterprise corresponds to a cooperative network of legally independent companies, which come together quickly and mainly contribute their essential skills in order 
to exploit a specific business opportunity, for example, provide an expected service or product on the basis of a common understanding of the business [2]. The virtual enterprises are more than just a collaboration among organizations, because they integrate essential skills and special abilities of their members in order to respond quickly to the market, with the following distinct characteristics: the lack of geographical boundaries, no barriers to information (as they make strong use of information and telecommunication technologies), fluid capacity for partnership and cooperation, and appearance to clients as a single existing organization.

Strader et al. [18] defined four stages in the life cycle of a virtual enterprise: Identification, Formation, Operation and Term (see Figure 1). The identification phase involves recognizing business opportunities, evaluate and select the business opportunity. These decisions are made sequentially. Identification stage ends once you have selected the best business opportunity available in the market. arrangement of these selected firms in the creation of the virtual organization.

Once the virtual organization is already formed, the operation phase begins. In the operation phase the most important decisions are taken, related to the following five functional areas: design, marketing, management, finance, manufacturing and distribution. When the market opportunity is already satisfied or has ceased to exist, the virtual organization is completed. The main decision-making processes in the End stage include the completion of the transaction and the dispersion of assets.

It is important to note the sequence of the life cycle, in the sense that once the partners are selected, they must stay within the virtual enterprise until the End stage, completely ignoring any problems that may be made in the Operation phase of the business network life cycle which require a revision of the participating partner companies. Also, the operating stage may leverage on potential new

\section{Virtual Enterprise Life-Cycle}

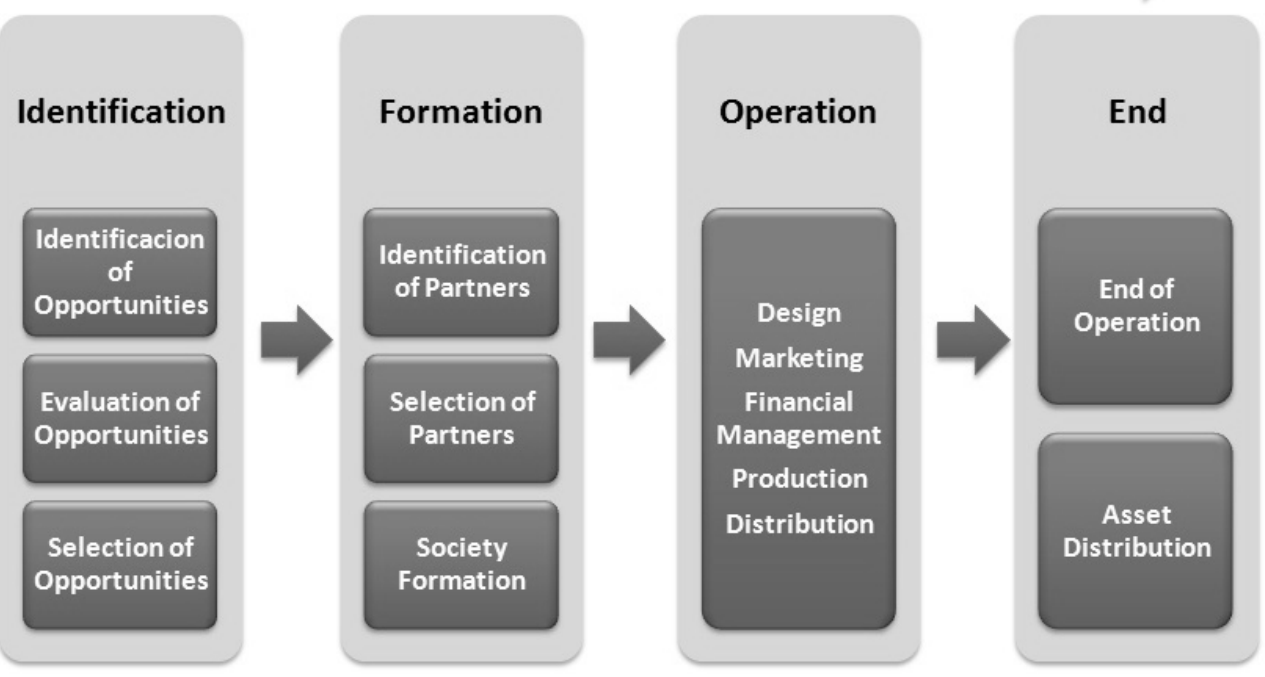

Figure 1. Virtual Enterprise Life-Cycle.

In the next phase, the most important decisions you make are, identification of partners, where it is necessary to identify potential partners and then make an assessment of them, and finally select the most appropriate, that will form a partnership between participating companies. The formation of the society implies an actual business opportunities; however, the model of Strader et. al. [18] does not allow a natural return to the stage of identification, but is required to give completion to the phases of Operation and End, and then explore potential new business opportunities. This contradicts 
one of the pillars of the conceptualization of virtual enterprises: the principle of agility.

The fact that a virtual organization depends heavily on comparative advantages of the modelling of business processes, where it defines how is the interpretation of messages, documents and services that travel across participating organizations. This becomes important in markets with strong social connotations, such as urban transportation of people.

\section{Urban Public Transportation}

The urban transportation of people is a key issue in the daily work of individuals. Transportation emerged as a result of the activities that typically people perform (labour, educational, recreational and spare-time activities, among many others). That is why it is necessary to apply every effort in developing efficient and effective projects, aimed at solving the problems of urban transportation. Among the alternatives available for this purpose, there are conventional systems for urban transportation of people, which often are associated with the use of buses that follow fixed routes and schedules. Their main advantage, low cost, is also a great disadvantage since a low tariff for the transportation service makes the routes to offer a very low flexibility (as in the established schedules.) As a counterpart, there is the taxi service, in which high flexibility in routes and schedules is greatly overshadowed by the high cost of operating the system (which is charged to the users of taxi services).

Finally, it also exists a type of transportation system with characteristics in-between the two above cases, that is, greater flexibility in routes and schedules in comparison with the traditional public urban transportation of people, and on the other hand, a service with lower operating costs than the taxi service. This intermediate operation schema of urban transportation of people corresponds to the Demand-Responsive Transportation (DRT). Currently, many DRTS initiatives (Demand-Responsive Transportation System) are being carried out, mainly in Europe and North America.

There are many types of DRTS [12]. Most of them agree that the same users are those who specify the conditions of travel, that is, starting point of the trip (place of user pickup by a vehicle), destination (place where the passenger has suggested as end of his trip), start travel time, time of arrival at destination, among others. If users do not send trip requests, the transport system has mechanisms to reduce the impact of these on the overall costs of system operation, for example, reduce vehicles circulating in the area of coverage, reschedule trips in order to reduce vehicles, drivers and miles travelled among some others.

The architecture of the DRTS includes a Travel Dispatch Centre for the allocation of trips to the available vehicles, and a reservation system to manage user requests of the transportation system. In addition, onboard units in each vehicle directly support the work of scheduling and allocating of these trips on each vehicle. There are also required communication systems and equipment to connect the Travel Dispatch Center with drivers (for example, via GPS devices).

The operation of a DRTS is consistent with the Figure 2, which shows a simplified process scheme of operation.

As the figure shows, a user of the transportation system in response to demand issues a request for transportation, which is hosted and managed by a transportation operator. A computer system belonging to the transportation operator is in charge of scheduling the travel request of the user within a travel itinerary. For doing so, a scheduling algorithm is used. The underlying problem of passenger transportation scheduling derivates from the Travelling Salesman Problem (TSP) and is a variant of the Pickup \& Delivery Problem (PDP) called Dial-a-Ride Problem (DARP). All of them are known to be NP-hard, reason why heuristics and meta-heuristics are used instead of exact methods, such as greedy algorithms, genetic algorithms [9], among other techniques. Each vehicle belonging to the fleet of vehicles from the transportation operator has a unique itinerary of travel. Depending on the conditions the itinerary of each vehicle, and the particular requirements of the user of the system, diverse travel suggestions are made.

The user can accept a proposed trip (confirming the reservation service), or may not accept it and may request a rescheduling of the travel or decline the order otherwise. The proposals' selection process for travel generated by the different transportation operators belonging to a network of transportation companies (as a virtual enterprise) has been studied and presented by Cabrera and Cubillos [10]. 


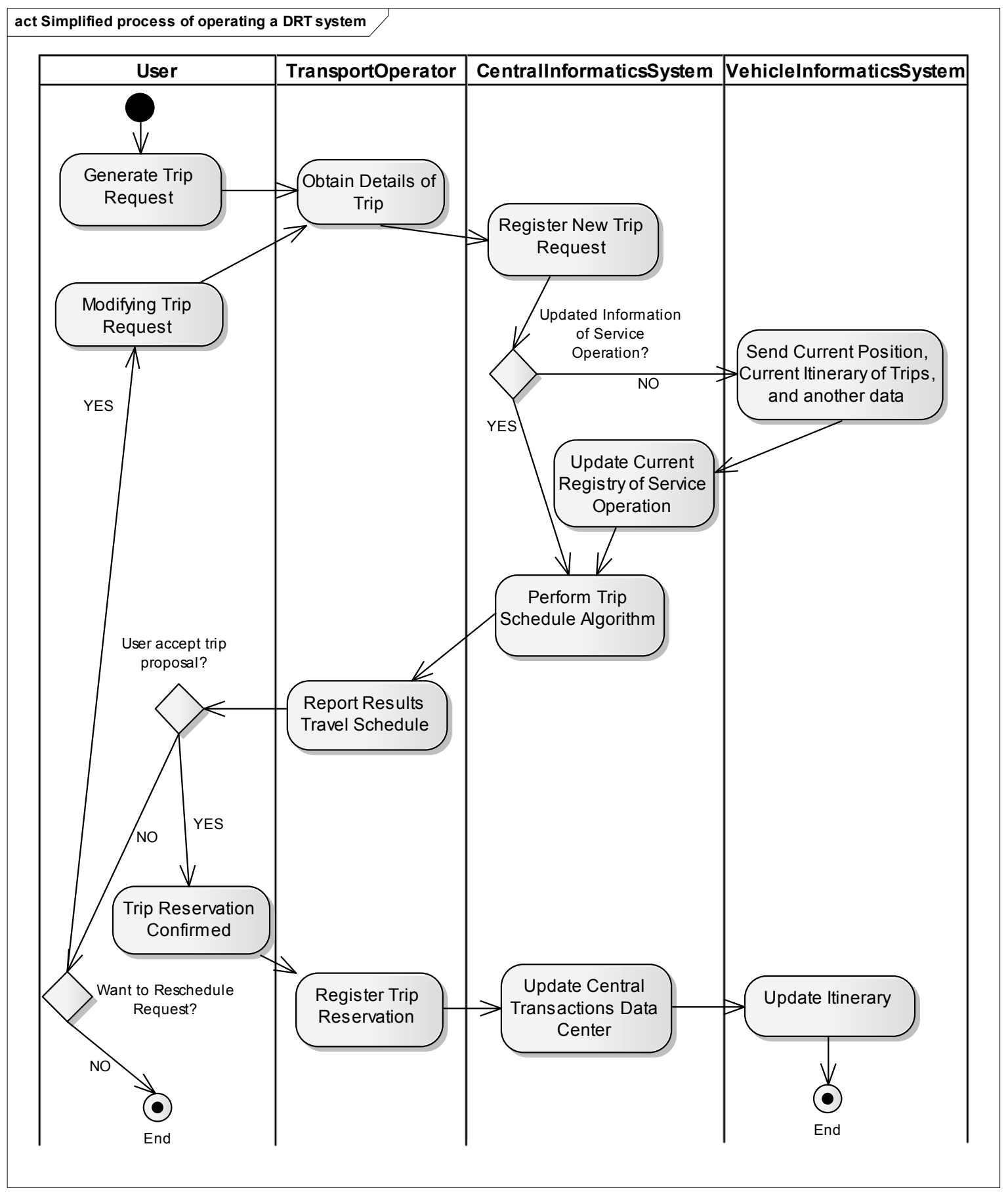

Figure 2. Simplified process of operating a DRT system.

However, an aspect not yet studied in depth corresponds to the process of formation of the virtual transportation enterprises, and above all, the administration of the conditions of keeping such transportation operators in the transportation virtual enterprise. In the same sense, it has not been studied how technology can assist in this regard.

\section{Model for Dynamic Formation and Operation of Virtual Organizations}

The formation process of a passenger transportation virtual enterprise must be substantiated in some key aspects, such as: transportation demand estimation (considering population size, availability of private cars, percapita income, among other variables), and the 
availability of transportation operators who are prepared to meet this demand for service. business. In the model of Speier et al. is highlighted the continued evaluation of the

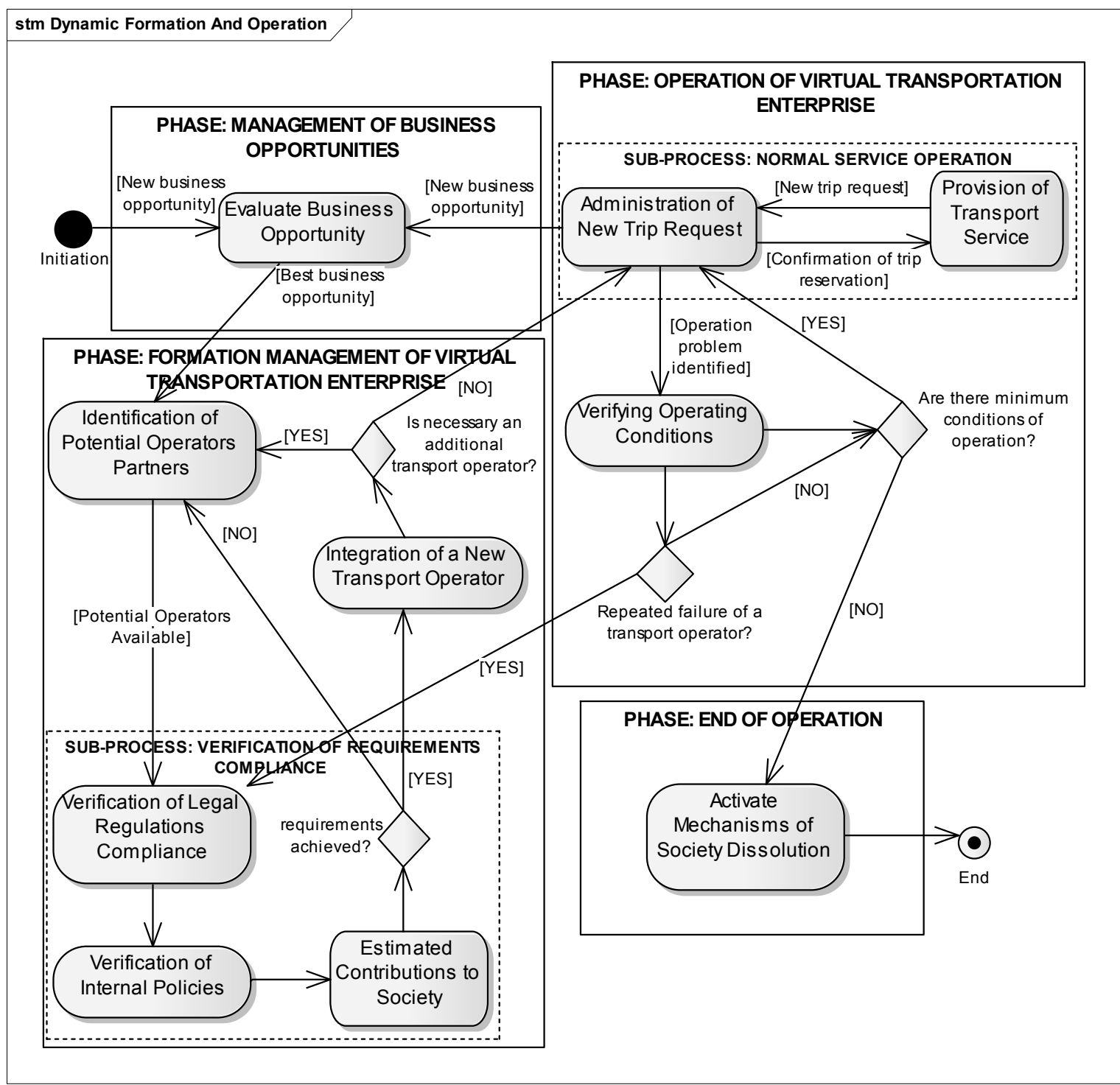

Figure 3. Dynamic Formation and Operation Model of a Virtual Transportation Enterprise.

Also, it is also necessary to check the continuity conditions of the virtual transportation business. To do this, a reference model is required that allows managing the training process and checks the continuity of its operation (see Figure 3). The above figure represents an ad-hoc adaptation of the life cycle model of a virtual enterprise presented by Strader et al. [18]. This paper proposes a model particularly oriented to the passenger transportation in response to demand. Note that the model adopted in this paper builds on an organizational scheme proposed by Speier et al. [17], called Central or Satellite model, where the central partner (in this case, a larger transportation operator) represents the greatest interest in the formation of a virtual company companies participating in the virtual network carried out by the central partner.

Referring to the proposed model, the first phase, called Management of Business Opportunities, is devoted to identifying and evaluating new business opportunities. A possible example of business opportunity is represented by the opening of a new transportation service for a geographical area with no service coverage up to that moment.

Once the best business opportunities available have been identified, it gives way to the next stage: Formation Management of the Virtual Transportation Enterprise. This second phase aims at identifying the best partners for the conformation of a transportation operator 
company. The acceptance of a new transportation operator partner is the implementation of a sub-process: Verification of Requirements Compliance. These requirements are regarding to the fulfilment of legal regulations in the operation of the transportation system (for example, compliance with labour laws), verification of internal policies within the network of transportation companies (for example, the existence of a minimum number of vehicles from a transportation operator's fleet), and estimates of potential additional contributions to the network of businesses by the candidate transportation operator. If these requirements are satisfied, the candidate transportation operator is integrated into the network of transportation operators. The process of identification and study of new transportation operators is executed until it is not longer necessary. operation. When the disadvantages associated with a particular transportation operator are repeatedly observed, the permanence of it is reviewed; in the three areas identified in Phase 2: compliance with legal regulations, verification of internal policies, and study of contributions to the network transportation companies. This review may result, for example, in a possible penalization of those transportation operators who do not offer a transportation service of quality, indirectly harming the rest of other transportation operators participating in the virtual enterprise.

Within the service quality metrics applied to the transportation operators the following can be found: service cost paid by users of the system associated to any transportation operator in particular, the number of vehicles provided by a transportation operator, number

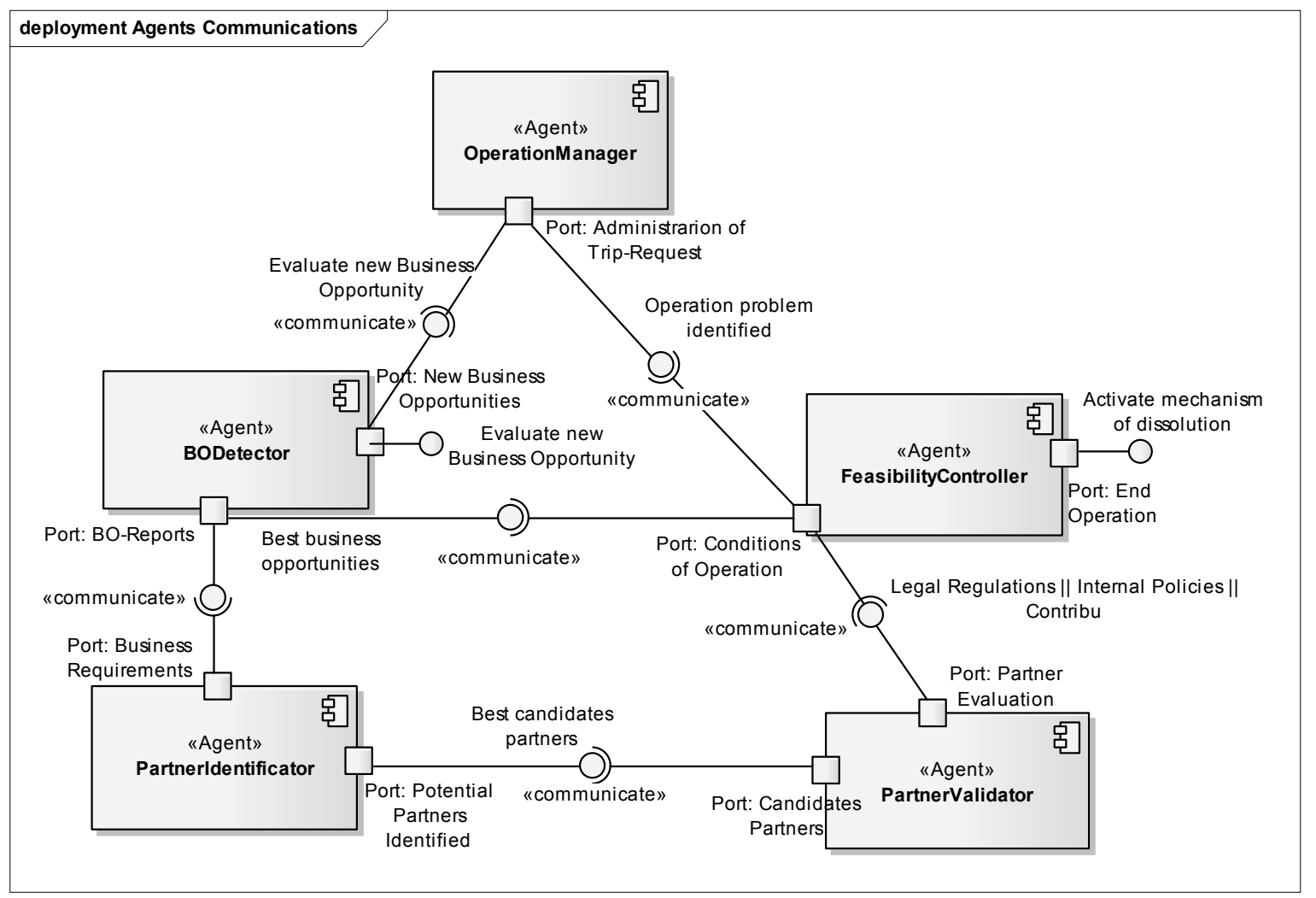

Figure 4. Agents Communications Schema of Dynamic Model for DRT-System.

Once the operational capacity to satisfy the demand for transportation service has been made available, the third phase begins: Operation of the Virtual Transportation Enterprise. The sub-process Normal Service Operation is executed until a problem is identified in the operation. This makes continuously the checking of the conditions of of passengers carried per vehicle, length of service (total travel duration for a passenger), the most important.

It is also possible that, in the Operation Phase of the Virtual Transportation Enterprise, a decline in the general conditions of operation of the system can be displayed and this will be conducive to a dissolution of the enterprise 
network. As a virtual company is not a fusion of enterprises, this solution only represents a breakthrough in collaborative work. Furthermore, it is also possible that during the operation of a Virtual Transportation Enterprise to identify new business opportunities. If such is the case, the necessary mechanisms are activated at the stage of Business Opportunities Management, along with the accordingly flow.

The Figure 4 shows a general schema based on agent technology for supporting a dynamic model for the formation and operation of a virtual transportation enterprise, in specific, for a demand-responsive modality (a DRTSystem). The general schema includes five agents, which are described in the following:

BODetector (BusinessDetector): Agent to recognize, classify and prioritize business opportunities for the virtual transportation enterprise. The following are within its scope: the estimation of the demand; the classification of the opportunities based on collect revenue, operating conditions, risk, and competition, among others.

It may also point out the business opportunities that benefit in the best way to the transportation virtual enterprise.

PartnerIdentificator: Its mission is to develop the profile of new members (new transportation operators) to be incorporated into the transportation virtual enterprise. This profile of new partners is developed considering the guidelines established by the BODetector agent, regarding the business opportunities identified and prioritized.

PartnerValidator: This agent must check the background of a new transportation operator before its incorporation into the virtual transportation enterprise. In relation to Figure 3 , this agent performs the process of "Verifying Requirements Compliance ".

FeasibilityController: This agent is responsible for verifying the sustainability of the operation of the transportation service. The conditions estimated by the BODetector agent are checked, in order to determine the feasibility of continuing with the normal operation of the virtual transportation enterprise. Failure in the achievement of the minimum standards of operation (for example, the existence of a number of requests per time unit), activates the dissolution of the virtual enterprise.
OperationManager: This agent manages the normal operation in the provision of the transportation service. Looking at special conditions in the operation, the agent sends information to the BODetector agent. With such objective this agent determines the existence of potential business opportunities. It also notices problems with the transportation operation, the OperationManager agent sends information to the FeasibilityController agent, so that the agent may check the feasibility to continue with the transportation operation, or whether it is advisable to examine in detail the service offered by a particular transportation operator, or even to activate the mechanisms of dissolution of the virtual company of transportation.

\section{Conclusion}

An approach towards a dynamic model for the conformation and operation of virtual organizations applied to case study of urban public transportation has been achieved. The proposed model incorporates flexibility in adding new operators, based on new business opportunities identified during the operation of the service. Also, the permanent revision allows the permanence of transportation operators within the coalition based on the quality of service they offer.

Additionally, technology allows lower hierarchical levels, particularly in the middle, so it generates mutual adjustment mechanisms, which adds dynamism to any structure, but these structures are complex.

Future work is bound mainly to the revision of this model and its practical implementation for the refinement of its processes and components. Currently, a parallel work is devoted to provide a mechanism and infrastructure for allowing a given Multiagent System (MAS) to become open, enabling the incorporation of newly incoming agents to participate within the existing society [21].

\section{Acknowledgements}

This work has been partially funded by CONICYT through Fondecyt Project No. 11080284 and by PUCV through its Nucleus Project No 037.215 "Collaborative Systems". 


\section{REFERENCES}

1. JAW J., A. R. ODONI, H. N. PSARAFTIS, N. H. M. WILSON, A Heuristic Algorithm for the Multi-Vehicle Advance-Request Dial-a-Ride Problem with Time Windows, Transportation Research B, Vol. 20B, 1986, pp. 243-57.

2. RUSS, C., G. VIERKE, Agent-Based Configuration of Virtual Enterprises. in: Advances in Artificial Intelligence, 22nd Annual German Conference on Artificial Intelligence, Bremen, Germany, 1998, pp. 15-17.

3. FINN, B., BENN, P., The Use of Transport Telematics in Inter-Urban and Rural Bus Services, Proceedings of the International Conference on Public Transport Electronic Systems. Conference Publication Series No. 425, 1996, pp. 5-10.

4. NELSON, J., F. SMITH, L. MORGAN, L. PICKUP, Evaluation of Telematics-Based Demand-Responsive Transport Services. Proceedings of the 4th World Congress on Intelligent Transport Systems, Berlin, Germany, 1997.

5. ARMitage, R., Does Dial-a-Ride Have Future?. Global Transport, Vol. 11, 1997, pp. 30-33.

6. FERNÁNDEZ, R., Análisis del Problema de Transporte Urbano. Revista Ciencia al Día Internacional, Vol. 2 (1), 1999.

7. ENOCH, M., S. ISON, R. LAWS, L. ZHANG, Evaluation Study of Demand Responsive Transport Services in Wiltshire. Reports of Studies, Public Transport Policies and Strategies, Wiltshire County Council, England, 2006.

8. BAHRAMI, A., Achieving Agile Enterprise Through Integrated Process Management: From Planning to Work Execution. Agents and Web Service Technologies in Virtual Enterprises. IGI Global, 2008, pp. 208-221.

9. CUBILlOS C., E. URRA, N. RODRÍGUEZ, Application of Genetic Algorithms for the DARPTW Problem. International Journal of Computers Communications \& Control, ISSN 18419836, 4(2),127-136, 2009.
10. CABRERA, D., C. CUBILlOS, MultiAgent Framework for a Virtual Enterprise of Demand-Responsive Transportation. Canadian Conference on AI, Springer-Verlag LNAI, Vol. 5032, 2008, pp. 66-71.

11. OSORIO, A., AFSARMANESH, H., CAMARINHA-MATOS, L., A Service Integration Platform for Collaborative Networks. in: Studies in Informatics and Control, Vol. 20, No. 1, 2011, pp. 19-30.

12. De ONA, J., Sistemas de Transporte Urbano a la Demanda. En: Optimizar la Gestión del Transporte Público Urbano: Un Paso Más Hacia la Sostenibilidad. Santander, España, 23-24 de Noviembre, 2006.

13. DEMCHENKO, Y., Virtual Organisations in Computer Grids and Identity Management. Elsevier Information Security Technical Report. Vol. 9 (1), 2004, pp. 59-76.

14. FOLINAS, D., T. PAVLOU, B. KARAKOSTAS, V. MANTHOU, A Conceptual Framework for Business Process Modeling in Virtual Organizations. Agents and Web Service Technologies in Virtual Enterprises. IGI Global, 2008, pp. 244-255.

15. RAHWAN, I., R. KOWALCZYK, Y. YANG, Virtual Enterprise Design - BDI Agents vs. Objects. Advances in Artificial Intelligence. PRICAI 2000 Workshop Reader, Springer Heidelberg LNCS, Vol. 2112, 2001, pp. 147-157.

16. PETERSEN, S., J. RAO, M. MATSKIN, Virtual Enterprise Formation Supported by Agents and Web Services. Agents and Web Service Technologies in Virtual Enterprises. IGI Global, 2008, pp. 46-64.

17. SPEIER, C., M. HARVEY, J. PALMER, Virtual Management of Global Marketing Relationships. Journal of World Business, vol. 33, issue 3, 1998, pp. 263-276.

18. STRADER, T., F. LIN, M. SHAW, Information Structure for Electronic Virtual Organization Management. Decision Support Systems, Vol. 23, 1998, pp. 75-94. 
19. WEISS, G., Multiagent Systems: A Modern Approach to Distributed Artificial Intelligence. MIT Press, Massachusetts, USA, 1999.

20. MINTZBERG, H., Diseño de Organizaciones eficientes. Ed. El Ateneo, Argentina, 1991.

21. CUBILlOS, C., M. DONOSO, N. RODRIGUEZ, F. GUIDI-POLANCO, D. CABRERA-PANIAGUA, Towards Open Agent Systems through Dynamic Incorporation. International Journal of Computers, Communications and Control, Vol. 5, 2010, pp. 675-683.
22. HERNANDEZ, J., J. MULA, R. POLER, J. PAVON, A Multiagent Negotiation Based Model to Support the Collaborative Supply Chain Planning Process. Studies in Informatics and Control, ISSN 1220-1766, vol. 20, issue 1/2011, pp. 43-54. 